\title{
Interventions to reduce antibiotic prescription for lower respiratory tract infections: Happy Audit study
}

\author{
Carl Llor, Josep M. Cots, Beatriz G. López-Valcárcel, Javier Arranz, \\ Guillermo García, Jesús Ortega, Manuel Gómez, Gloria Guerra, \\ María J. Monedero, Juan D. Alcántara, José Paredes, Silvia Hernández, \\ Marina Cid, Carolina Pérez and Vicenta Pineda
}

ABSTRACT: This before-after study aimed to evaluate the effect of two interventions on lowering the prescription of antibiotics in lower respiratory tract infections (LRTI) in Spain.

General practitioners (GPs) registered all cases with LRTIs over 3-week periods before and after an intervention, in 2008 and 2009. Two types of intervention were considered: fullintervention group (FIG), consisting of discussion sessions of the results of the first registry, courses for GPs, guidelines, patient information leaflets, workshops on rapid tests and use of the C-reactive protein (CRP) test; GPs in the partial-intervention group (PIG) underwent all of the above interventions except for the workshop on rapid tests, and they did not have access to CRP. A multilevel logistic regression analysis was performed considering the prescription of an antibiotic as the dependent variable.

210 physicians were assigned to FIG and 70 to PIG. In 2009, 58 new physicians were included as a control group. 5,385 LRTIs were registered. Compared with the control group, the OR of antibiotic prescription after the intervention in the PIG was 0.42 (95\% Cl: $0.22-0.82)$ and 0.22 (95\% Cl: 0.12-0.38) in the FIG.

Intervention led to a reduction in the prescription of antibiotics, mainly when CRP testing was available.

KEYWORDS: Antibiotics, audit, C-reactive protein, lower respiratory tract infections

$\mathbf{U}$ nnecessary use of antibiotics plays an important role in increasing bacterial resistance and medical costs, as well as the risk of drug-related adverse events [1]. The most frequent indication for antibiotic prescription in the north-western hemisphere is lower respiratory tract infections (LRTI) [2]. Acute bronchitis accounts for $80 \%$ of LRTIs [3, 4], and despite evidence of little or no benefit of antibiotics, approximately three-quarters of LRTIs are treated with antimicrobial agents in most countries in the north-western hemisphere [5-7]. Clinical signs and symptoms are unreliable for distinguishing viral from bacterial LRTIs [8, 9]. Diagnostic uncertainty increases the likelihood of inappropriate antibiotic prescription and, when in doubt, general practitioners (GPs) opt for antibiotic prescription in case of possible pneumonia, since routine chest radiography for all patients with LRTI is neither feasible nor appropriate in primary care [10]. C-reactive protein $(\mathrm{CRP})$ is a promising biomarker for improving the assessment of LRTI in primary care and has been shown to perform better in predicting the diagnosis of pneumonia than any individual or combined clinical symptoms and signs in LRTI $[11,12]$. The CRP rapid test is feasible and easy to perform in the community setting, since it takes $\sim 3$ min to obtain the result, it can utilise serum, plasma or whole blood, organised laboratories are not needed, and it can be used by clinicians or nursing staff [13]. Moreover, studies comparing this rapid test with the routine CRP laboratory test have shown a very good correlation, thereby demonstrating its reliability [14].

Few studies have evaluated the role of these rapid tests on antibiotic prescription in primary care. Furthermore, these studies were performed in countries with low rates of antibiotic prescription [15-20]. Compared with other European countries, Spain has historically had a high outpatient antimicrobial consumption rate and a high proportion of respiratory microorganisms
AFFILIATIONS

For author affiliations, see the Acknowledgements section.

CORRESPONDENCE

C. Llor

Primary Healthcare Centre Jaume I

c. Felip Pedrell

45-47

Tarragona

Catalonia 43005

Spain

E-mail: carles.llor@urv.cat

Received:

June 012011

Accepted after revision:

Nov 242011

First published online:

Dec 192011 
with resistance to common antibiotics, although this has progressively decreased in recent years [21, 22]. The aim of this study was to evaluate the effect of two interventions on lowering the prescription of antibiotics in LRTIs in primary care in Spain.

\section{MATERIALS AND METHODS Study population}

A prospective non-randomised controlled before-after study was performed in primary care clinics in Spain. This study constitutes part of the Happy Audit project, a study financed by the European Commission, the main objective of which was to strengthen the surveillance of respiratory tract infections in primary healthcare through the development of intervention programmes targeting GPs and changing people's habits towards prudent use of antimicrobial agents [23]. GPs from six countries have participated in this study (Denmark, Sweden, Lithuania, Russia, Spain and Argentina). However, Spain was the only country in which two types of interventions were undertaken. The interventions only differed in the training and access to the use of a CRP point-of-care test.

Detailed information about the study method and the intervention were previously published in the study protocol [23]. Briefly, the data were registered according to the methodology of the Audit Project Odense described by MuNCK et al. [24], which follows a prospective self-registration methodology in which a simple reporting sheet is used. Approval was obtained from the Ethical Committee Board Fundació Jordi Gol i Gurina (Barcelona, Spain; registration number: 44154). All participants were instructed to fill out a template with all LRTI patients during a 3-week period in the winter months of 2008 (first registry) and 2009 (second registry), covering a total of 15 working days in both periods. On this sheet, the physician attending the patient noted different specific parameters of medical care, including the age and sex of the patient, the number of days of symptoms, presenting signs (fever, coughing, dyspnoea, increase in sputum volume, purulence of sputum), diagnosis (acute bronchitis, acute exacerbation of chronic bronchitis or chronic obstructive pulmonary disease (COPD), pneumonia), aetiologic suspicion (viral or bacterial), performance of chest radiograph and CRP rapid tests, antibiotic treatment or not, allergy or not to penicillin, and whether the patient requested an antibiotic and referral to another healthcare setting.

Three groups of professionals were included. 1) A fullintervention group (FIG), made up of GPs from eight autonomous communities. This intervention consisted of presentation sessions and discussion of the results of the first registry, training courses on the diagnosis and treatment of LRTIs, discussion of guidelines, patient information leaflets, workshops on rapid tests and the introduction of the CRP test in the consulting office. The workshops took place $\sim 2$ months before the second registry. Physicians were instructed not to use CRP as a stand-alone test but rather to use it as an additional test in case of doubt, withholding antibiotic therapy with $\mathrm{CRP}$ values $<20 \mathrm{mg} \cdot \mathrm{L}^{-1}$ and prescribing an antibiotic with values $>100 \mathrm{mg} \cdot \mathrm{L}^{-1}$. 2) Another group of GPs from Catalonia was assigned to a partial-intervention group (PIG), which included all of the above interventions except for the workshop on diagnostic methods and CRP tests. 3) The control group included professionals from two other autonomous communities who only did the registry in 2009, with no previous intervention.

\section{Statistical analysis}

The data were analysed with the Stata v.11 (Statacorp, College Station, TX, USA) statistical programme, performing univariate descriptive statistics and homogeneity tests of antibiotic prescription for each group among the physicians who completed the study and those who did not. A multilevel logistic regression model was estimated with two levels: the patients with LRTIs and the physicians. Antibiotic prescription was considered as a dependent variable. The variables of interest were the use of CRP and the five clusters of physicians (control group, the FIG before and after the intervention, and the PIG before and after the intervention). The model was also adjusted for covariables: age and sex, days with symptoms, signs presented, diagnosis, patient demand for antibiotics, request for radiograph, and radiographic results positive for consolidation. The physician effect was modelled as a random intercept and, in addition, the model included a specific random effect on the FIG after the intervention. Once the model had been estimated, the Bayesian posterior predictor of both random effects was calculated [25]. Statistical significance was considered at a p-value of $<0.05$.

\section{RESULTS}

A total of 332 GPs were invited to participate in the study in 2008, with 235 being assigned to the FIG and 97 to the PIG. Of these two groups, a total of $308(92.8 \%)$ physicians registered LRTIs in the first audit in 2008 and 280 (84.4\%) professionals carried out the intervention in 2008 and made the second registry in 2009. Figure 1 shows the general scheme of the study. The five groups of physicians registered a total of 5,385 LRTIs, of which $3,624(67.3 \%)$ corresponded to acute bronchitis. As shown in table 1, antibiotic prescription was greater in the control group $(76.6 \%)$ and in the pre-intervention groups (FIG: 69\%; PIG: 61.3\%); it was lower after the intervention ( $43.9 \%$ versus $56.2 \%$, respectively). By diagnosis, the greatest percentage reductions were observed in acute bronchitis in the FIG (from $62.3 \%$ to $30.2 \%$ ) (table 1 ).

\section{CRP test results}

The CRP test was only used by the physicians in the FIG after the intervention, with 545 determinations of a total of 1,488 $(36.6 \%)$ contacts. However, the numerical value was not noted or was illegible in 51 cases. Antibiotic prescription was lower among the physicians using the CRP rapid test $(43.9 \%)$ compared with the GPs who did not use the test $(61.8 \%$; $p<0.001)$. Prescription was also lower when the results of CRP were $<10 \mathrm{mg} \cdot \mathrm{L}^{-1}$, with these values being observed in $51.2 \%$ of the total number of determinations noted in the registry sheets and, in these cases, antibiotics were only prescribed in 35 $(13.8 \%)$ contacts out of a total of 253 determinations (table 2).

\section{Predictors of antibiotic prescription in LRTIs}

A multilevel logistic regression model of two levels was estimated including contacts with LRTIs $(n=5,385)$ and physicians $(n=338)$. In this analysis the use of the CRP was a very significant protective factor for antibiotic prescription (table 3). Thus, with CRP results $<10 \mathrm{mg} \cdot \mathrm{L}^{-1}$ the OR for 
Full-intervention group

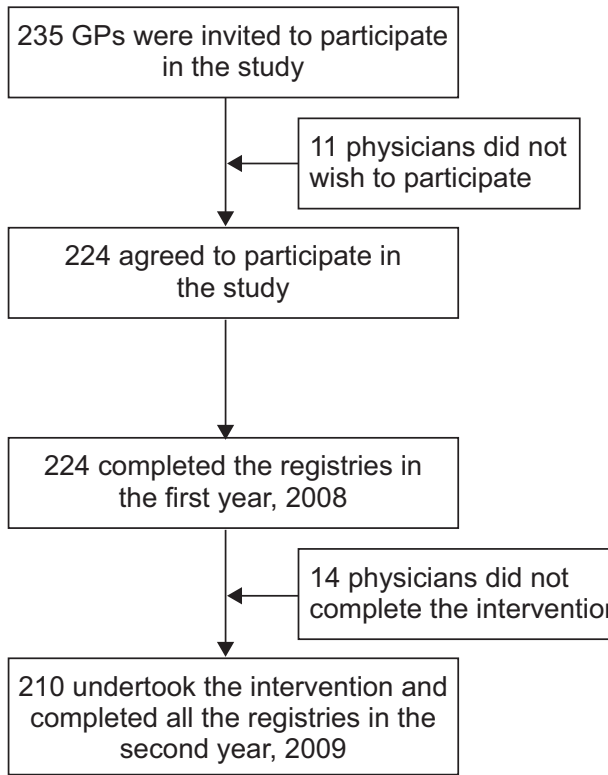

Partial-intervention group

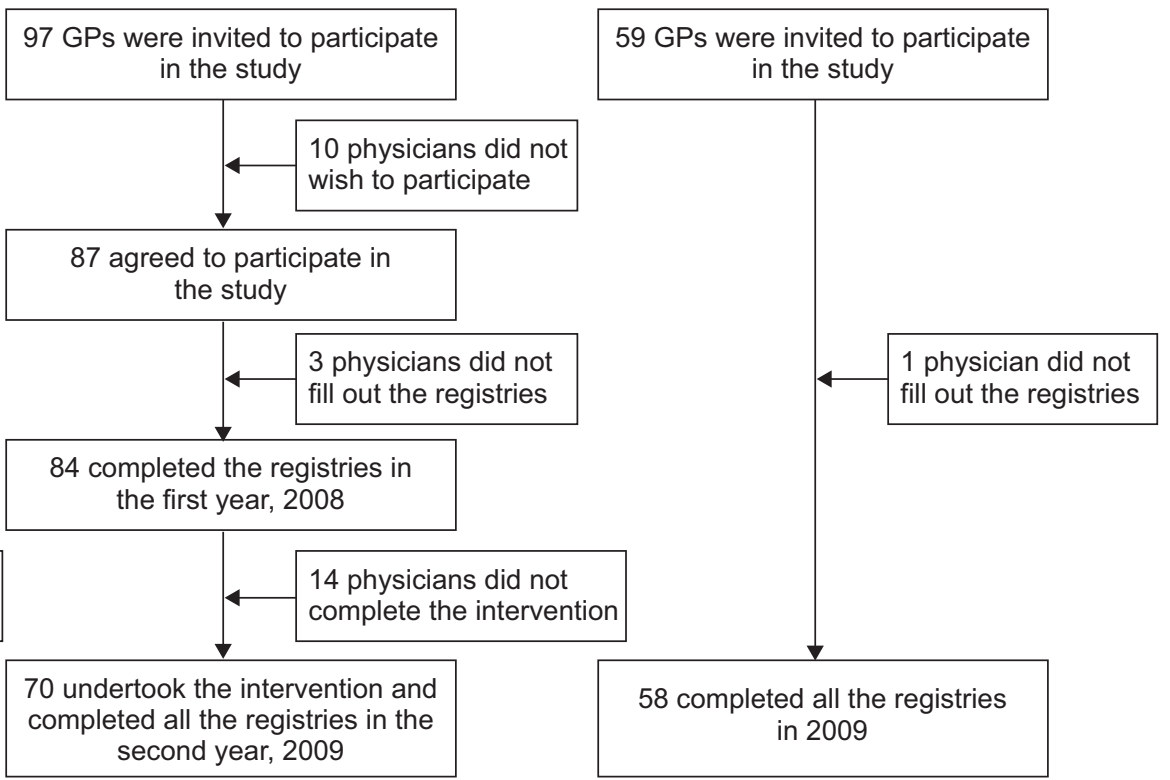

FIGURE 1. General scheme of the study. GPs: general practitioners.

antibiotic prescription was 0.10 (95\% CI 0.06-0.17) compared with the non-use of this test. After adjusting for the remaining variables, no statistically significant differences were found in antibiotic prescription between the two pre-intervention and the control groups. In contrast, the post-intervention ORs were significantly lower than those of the control and pre-intervention groups. In comparison with the control group, the OR of 0.42 (95\% CI 0.22-0.82) for antibiotic prescription was significant in the PIG after the intervention. The effect of the intervention was greater with the use of CRP, with an OR of 0.22 (95\% CI 0.12-0.38) for antibiotic prescription observed in the FIG after the intervention.

Estimation results indicate that the physician effect was very significant (Chi-squared 574.3; $\mathrm{p}<0.0001$ ), indicating a great random heterogeneity between the physicians in antibiotic prescription after adjusting for all the previously mentioned covariables. The random effect on the intercept differed significantly between the groups of physicians (ANOVA, $\mathrm{p}<0.001$ ). In addition, the random effect of the GPs was significant, differing in the FIG after the intervention from the remaining groups. With respect to the constant and the slope, both random effects were negatively correlated $(-0.68)$, indicating that, in general, the effect of the intervention was greater among physicians who prescribed antibiotics more frequently. Therefore, the full intervention homogenised the behaviour of the physicians. The partial intervention, on the other hand, did not present a differentiated significant random effect.

\section{DISCUSSION}

This study demonstrates that an intervention aimed at promoting a more prudent use of antibiotics for LRTIs by GPs can reduce the prescription of antibiotics, mainly in acute bronchitis, with this reduction being much greater when these professionals are offered the possibility of performing CRP tests in their offices.

\section{Strengths and limitations of the study}

The results of this study should be interpreted with caution because of a series of limitations. First, this is a study in which

TABLE 1 Antibiotic prescription in lower respiratory tract infections in the different groups of general practitioners

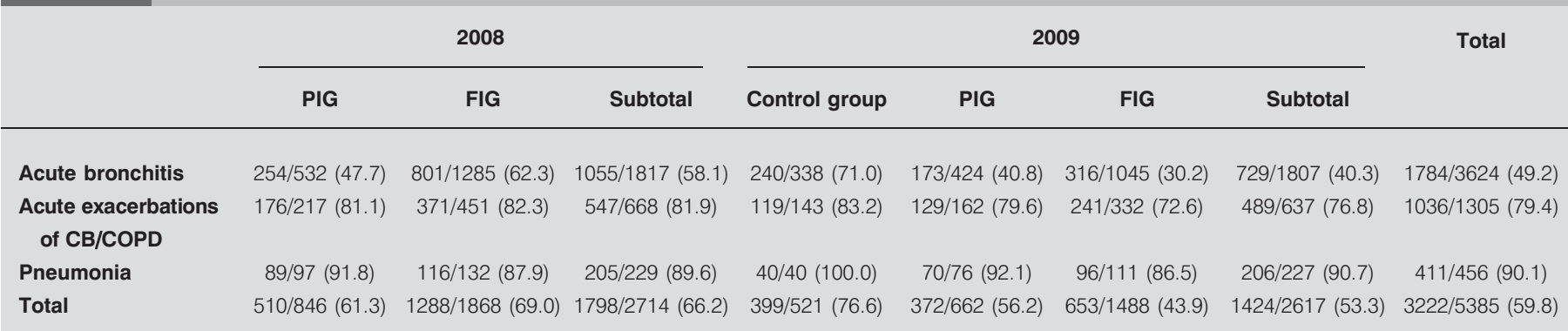

Data are presented as n/N (\%). PIG: partial-intervention group; FIG: full-intervention group; CB: chronic bronchitis; COPD: chronic obstructive pulmonary disease. 


\begin{tabular}{ll} 
TABLE 2 & $\begin{array}{l}\text { Antibiotic prescription in lower respiratory tract } \\
\text { infections according to C-reactive protein (CRP) } \\
\text { value obtained }\end{array}$ \\
Use of CRP test & Antibiotic prescription \\
\hline No use of CRP & $2992 / 4840(61.8)$ \\
Use of CRP & $35 / 253(13.8)$ \\
$0-10 \mathrm{mg} \cdot \mathrm{L}^{-1}$ & $16 / 28(57.1)$ \\
$11-20 \mathrm{mg} \cdot \mathrm{L}^{-1}$ & $168 / 213(78.9)$ \\
$>20 \mathrm{mg} \cdot \mathrm{L}^{-1}$ & $20 / 51(51.0)$ \\
Figure not written or illegible & $239 / 545(43.9)$ \\
Total & \\
\hline &
\end{tabular}

physicians, including those assigned to the control group, have participated voluntarily, thus their prescription habits may not be the same as those followed globally by primary care physicians. Different studies have shown that GPs who participate in audits may be more interested in research than other physicians [26]. The results of this study are based on the data reported by the GPs and even though these data were not double-checked with the actual prescription, the results obtained by the pre-intervention groups were similar to or slightly lower than those obtained in observational studies carried out in Spain [27-29]. Participation in a study on the rational use of antibiotics may have also influenced the GP to prescribe antibiotics more rationally in the first registry. Another limitation is that possible associated comorbidities of the patients registered were not taken into account, and this may influence the percentage and the type of antibiotic used. Likewise, not all the signs and symptoms of LRTIs were considered, although the most important were, as well as all those described in the medical literature as making bacterial aetiology more probable. Nor did we consider all the nonbiomedical factors that some studies have described, such as the fact that one of the most powerful predictors of antibiotic prescription is inherent to the physicians themselves, who prescribe more than the clinical manifestations of the patient suggest. Our study suggests that the predisposition to prescribe varies greatly among physicians. Another limitation of the study was that the clinical outcomes of the patients were not taken into account and thus it is not known whether the percentage of complications or clinical failure differed between groups. However, CALS and co-workers $[19,20]$ did not observe any differences in clinical outcomes between patients with LRTI who were treated with antibiotics and those who were not. The goal of primary care is not to minimise antibiotic prescription but rather to prescribe antimicrobial agents to patients who truly need them and avoid inappropriate prescription decisions. Although we did not measure health outcomes, the registry sheet included the referral of patients to hospital. Although this was not a clinical trial, which may also be considered a limitation of the study, we analysed the results with multivariate multilevel analysis, which allowed comparison of the GPs and determination of whether the effect of the intervention reduced not only antibiotic prescription but also the variability among physicians.

\begin{tabular}{|c|c|c|c|}
\hline \multirow{2}{*}{$\begin{array}{l}\text { TABLE } 3 \\
\text { Variable }\end{array}$} & \multicolumn{3}{|c|}{$\begin{array}{l}\text { Odds ratio for antibiotic prescription in lower } \\
\text { respiratory tract infections }\end{array}$} \\
\hline & & OR $(95 \% \mathrm{Cl})$ & p-value \\
\hline \multicolumn{2}{|l|}{ Age } & $1.012(1.007-1.017)$ & 0.000 \\
\hline \multicolumn{2}{|l|}{ Male sex } & $1.103(0.928-1.309)$ & 0.265 \\
\hline \multicolumn{2}{|l|}{ COPD } & $2.883(2.275-3.653)$ & 0.000 \\
\hline \multicolumn{2}{|l|}{ Fever } & $4.667(3.813-5.712)$ & 0.000 \\
\hline \multicolumn{2}{|l|}{ Cough } & $1.058(0.809-1.384)$ & 0.679 \\
\hline \multicolumn{2}{|c|}{ Increase in dyspnoea } & $1.390(1.152-1.677)$ & 0.001 \\
\hline \multicolumn{2}{|c|}{ Increase in sputum } & $2.369(1.962-2.860)$ & 0.000 \\
\hline \multicolumn{2}{|c|}{ Purulent sputum } & $10.068(8.079-12.521)$ & 0.000 \\
\hline \multicolumn{2}{|c|}{ Demand for antibiotics } & $3.02(1.668-5.468)$ & 0.000 \\
\hline \multicolumn{2}{|c|}{ Request for a radiograph } & $1.602(1.142-2.247)$ & 0.006 \\
\hline \multicolumn{2}{|c|}{ Radiograph positive for consolidation } & $8.07(4.232-15.387)$ & 0.000 \\
\hline \multicolumn{4}{|l|}{ CRP level\# } \\
\hline \multicolumn{2}{|c|}{$<10 \mathrm{mg} \cdot \mathrm{L}^{-1}$} & $0.103(0.061-0.173)$ & 0.000 \\
\hline \multicolumn{2}{|c|}{$10-20 \mathrm{mg} \cdot \mathrm{L}^{-1}$} & $1.488(0.542-4.08)$ & 0.440 \\
\hline \multicolumn{2}{|c|}{$>20 \mathrm{mg} \cdot \mathrm{L}^{-1}$} & $4.6(2.781-7.606)$ & 0.000 \\
\hline \multicolumn{2}{|c|}{ Missing or illegible } & $0.396(0.182-0.859)$ & 0.019 \\
\hline \multicolumn{4}{|c|}{ Partial-intervention group $\pi$} \\
\hline \multicolumn{2}{|c|}{ Pre-intervention } & $0.574(0.298-1.104)$ & 0.096 \\
\hline \multicolumn{2}{|c|}{ Post-intervention } & $0.424(0.219-0.821)$ & 0.011 \\
\hline \multicolumn{4}{|c|}{ Full intervention group ${ }^{\pi}$} \\
\hline \multicolumn{2}{|c|}{ Pre-intervention } & $0.811(0.461-1.426)$ & 0.466 \\
\hline \multicolumn{2}{|c|}{ Post-intervention } & $0.217(0.123-0.382)$ & 0.000 \\
\hline
\end{tabular}

The greatest strength of this study is the large number of physicians included. In addition, $<10 \%$ of the professionals who carried out the first registry abandoned the study. Another strength of this study is inherent to the reality of our country in that the CRP test is not used in primary care offices and therefore the effect of its use can be better established and can also be compared with the partial intervention.

\section{Comparison with other studies}

Many studies have been performed to determine the effectiveness of different types of interventions to reduce the prescription of antibiotics in respiratory tract infections. Not all interventions achieve positive results, particularly when used alone. According to a Cochrane Library review, only interventions taking combinations of these into account, such as result feedback, interactive educational sessions and strategies aimed at patients, achieve a reduction in the prescription of antibiotics in supposedly viral respiratory infections [30]. The use of printed educational material or audit and feedback alone resulted in no or only small changes in prescribing. Interactive educational meetings, such as those undertaken in this study, appear to be more effective than didactic lectures. Despite multifaceted interventions combining physician, patient and public education being the most successful in reducing antibiotic prescribing for inappropriate indications, the effectiveness of these interventions is, in fact, only modest [30].

Nonetheless, to date, few studies have been performed to determine the modification in antibiotic prescription in LRTIs 
with the introduction of rapid tests, and in these cases, the reduction in antibiotic prescription is usually more important than with other types of intervention. ANDRÉ et al. [18] demonstrated that the prescription of antibiotics in paediatric offices in Sweden may be reduced from $58 \%$ among physicians not using the CRP test to $36 \%$ when this technique is available. In another study, GPs assigned to CRP testing safely reduced antibiotic prescription for LRTIs compared with doctors assigned to usual care (from 53\% to 31\%) [19]. In a recently published study carried out in the Netherlands, patients in the CRP-assisted group used fewer antibiotics than control patients ( $43.4 \%$ versus $56.6 \%$, respectively) [20]. One advantage of our design is that it allows the effect of the audit per se to be estimated separately from the availability of CRP testing. The reduction in antibiotic prescription associated with the additional availability of the test is more marked in our study than in others.

The diagnosis of pneumonia is difficult in general practice because the symptoms of the disease frequently resemble those of other LRTIs [31]. The CRP value has been found to be more valuable than any sign or symptom in differentiating pneumonia from other respiratory tract infections [11, 12]. A CRP test result adds incremental information to the physicians' information obtained from medical history and physical examination. The relation of CRP with an infiltrate on chest radiography as a reference standard shows an area under the receiver operating characteristic (ROC) curve of 0.80 [32]. The addition of CRP to a model based on signs and symptoms increases the area under the ROC curve from 0.70 to 0.90 [12]. In particular, a low CRP test result $\left(<20 \mathrm{mg} \cdot \mathrm{L}^{-1}\right)$, which was the case in $>50 \%$ of our patients, may be helpful in excluding illness necessitating antibiotic treatment. In the present study, the GPs performing the determination of CRP with results $<10 \mathrm{mg} \cdot \mathrm{L}^{-1}$ were 10 -fold less likely to prescribe antibiotics than physicians who did not use the rapid test. In a Swedish study, $14 \%$ of patients with a diagnosis of nonspecific respiratory tract infection were given antibiotics when the CRP value was $<10 \mathrm{mg} \cdot \mathrm{L}^{-1}$ compared with $94 \%$ when the CRP value was $>50 \mathrm{mg} \cdot \mathrm{L}^{-1}$ [17]. More than half the cases with values $>10$ $\mathrm{mg} \cdot \mathrm{L}^{-1}$ were prescribed antibiotics, even with values between 10 and $20 \mathrm{mg} \cdot \mathrm{L}^{-1}$. The antibiotic prescription rate in our study was not reduced when CRP had intermediate levels $\left(20-99 \mathrm{mg} \cdot \mathrm{L}^{-1}\right)$, similar to the study by CALS et al. [20].

Having incorporated two levels (contacts with LRTIs and GPs), our model allowed estimation of the predisposition to prescribe antibiotics of each physician. There was a high degree of heterogeneity among GPs with respect to the trend to prescribe antibiotics, which was reduced when CRP testing was provided. Nevertheless, the partial intervention based on the discussion of results, courses for GPs and leaflets for patients did not apparently reduce the intrinsic heterogeneity of the prescription habits of the physicians.

\section{Implications for future research}

Having determined physician behaviour regarding antibiotic prescription for LRTIs it is necessary to know whether these results can be maintained in the future with observation of the behaviour of the same physicians several years after the introduction of the CRP rapid tests. This should also be reproduced in other geographical areas with different healthcare systems and different antibiotic prescription behaviours. Qualitative investigation is required to determine why physicians do not reduce their antibiotic prescription behaviour with intermediate CRP concentrations. Future studies will also better define the CRP cut-off points to be used to safely withhold antibiotic therapy. Only in this way will we be able to carry out strategies to change the attitudes of GPs and encourage rational use of antibiotics in these infections.

\section{Conclusion}

The results of the present study demonstrate that a reduction may be achieved in the prescription of antibiotics, particularly in acute bronchitis, with the implementation of a simple methodology aimed at encouraging the prudent use of antibiotics in LRTIs, including feedback and discussion of baseline antibiotic prescription, training courses in the diagnosis of treatment of LRTIs, discussion of guidelines, and patient information leaflets. Moreover, this reduction may be greater with the availability of CRP tests in consultation offices. We believe that the pragmatic nature of our study enhances the generalisability of the results to other countries where these rapid tests are not routinely used.

\section{SUPPORT STATEMENT}

This project is a Specific Targeted Research Project (STREP) funded by the European Commission: DG SANCO under the Frame Program 6 (SP5A-CT-2007-044154). Contract Number 044154.

\section{STATEMENT OF INTEREST}

None declared.

\section{ACKNOWLEDGEMENTS}

Author affiliations are as follows: C. Llor: University Rovira i Virgili, Primary Healthcare Centre Jaume I, Tarragona, Spain; J.M. Cots: University of Barcelona, Primary Healthcare Centre La Marina, Barcelona, Spain; B.G. López-Valcárcel: Dept of Quantitative Methods for Economics and Management, University of Las Palmas, Las Palmas, Spain; J. Arranz: Primary Healthcare Centre Arquitecte Bennàssar, Palma de Mallorca, Spain; G. García: Primary Healthcare Centre La Calzada II, Gijón, Spain; J. Ortega: Primary Healthcare Centre Rincón de Soto, La Rioja, Spain; M. Gómez: Primary Healthcare Centre San Cristóbal, Madrid, Spain; G. Guerra: Primary Healthcare Centre Escaleritas, Las Palmas de Gran Canaria, Spain; M.J. Monedero: Primary Healthcare Centre Rafalena, Castelló, Spain; J.D. Alcántara: Primary Healthcare Centre Bollulos Par del Condado, Huelva, Spain; J. Paredes: Primary Healthcare Centre Hostalrich, Girona, Spain; S. Hernández: Primary Healthcare Centre Jaume I, Tarragona, Spain; M. Cid: Primary Healthcare Centre Teis, Vigo, Spain; C. Pérez: Primary Healthcare Centre Puntales, Cádiz, Spain; V. Pineda: Primary Healthcare Centre Serrería I, Valencia, Spain.

\section{REFERENCES}

1 Wenzel RP. The antibiotic pipeline: challenges, costs, and values. N Engl J Med 2004; 351: 523-526.

2 Mizgerd JP. Acute lower respiratory tract infection. $N$ Engl J Med 2008; 358: 716-727.

3 Woodhead M, Blasi F, Ewig S, et al. Guidelines for the management of adult lower respiratory tract infections. Eur Respir J 2005; 26: $1138-1180$.

4 Smucny J, Fahey T, Becker L, et al. Antibiotics for acute bronchitis. Cochrane Database Syst Rev 2004; 4: CD000245.

5 Gonzales R, Steiner JF, Sande MA. Antibiotic prescribing for adults with colds, upper respiratory tract infections, and bronchitis by ambulatory care physicians. JAMA 1997; 278: 901-904. 
6 Kuyvenhoven MM, Verheij TJ, de Melker RA, et al. Antimicrobial agents in lower respiratory tract infections in Dutch general practice. Br J Gen Pract 2000; 50: 133-134.

7 Macfarlane J, Lewis SA, Macfarlane R, et al. Contemporary use of antibiotics in 1089 adults presenting with acute lower respiratory tract illness in general practice in the UK: implications for developing management guidelines. Respir Med 1997; 91: 427-434.

8 Hopstaken RM, Stobberingh EE, Knottnerus JA, et al. Clinical items not helpful in differentiating viral from bacterial lower respiratory tract infections in general practice. J Clin Epidemiol 2005; 58: 175-183.

9 Graffelman AW, Knuistingh Neven A, le Cessie S, et al. A diagnostic rule for the aetiology of lower respiratory tract infections as guidance for antimicrobial treatment. Br J Gen Pract 2004; 54: 20-24.

10 McIsaac WJ, Butler CC. Does clinical error contribute to unnecessary antibiotic use? Med Decis Making 2000; 20: 33-38.

11 Melbye H, Straume B, Aasebo U, et al. The diagnosis of adult pneumonia in general practice. The diagnostic value of history, physical examination and some blood tests. Scand J Prim Health Care 1988; 6: 111-117.

12 Hopstaken RM, Muris JW, Knottnerus JA, et al. Contributions of symptoms, signs, erythrocyte sedimentation rate, and C-reactive protein to a diagnosis of pneumonia in acute lower respiratory tract infection. Br J Gen Pract 2003; 53: 358-364.

13 Seamark DA, Backhouse SN, Powell R. Field-testing and validation in a primary care setting of a point-of-care test for C-reactive protein. Ann Clin Biochem 2003; 40: 178-180.

14 Esposito S, Tremolati E, Begliatti E, et al. Evaluation of a rapid bedside test for the quantitative determination of C-reactive protein. Clin Chem Lab Med 2005; 43: 438-440.

15 Bjerrum L, Gahrn-Hansen B, Munck AP. C-reactive protein measurement in general practice may lead to lower antibiotic prescribing for sinusitis. Br J Gen Pract 2004; 54: 659-662.

16 Diederichsen HZ, Skamling M, Diererichsen A, et al. Randomised controlled trial of CRP rapid test as a guide to treatment of respiratory infections in general practice. Scand J Prim Health Care 2000; 18: 39-43.

17 André M, Schwan A, Odenholt I, et al. The use of CRP tests in patients with respiratory tract infections in primary care in Sweden can be questioned. Scand J Infect Dis 2004; 36: 192-197.

18 André M, Eriksson M, Mölstad S, et al. The management of infections in children in general practice in Sweden: a repeated 1week diagnosis-prescribing study in 5 counties in 2000 and 2002. Scand J Infect Dis 2005; 37: 863-869.

19 Cals JW, Butler CC, Hopstaken RM, et al. Effect of point of care testing for $\mathrm{C}$ reactive protein and training in communication skills on antibiotic use in lower respiratory tract infections: cluster randomised trial. BMJ 2009; 338: b1374.
20 Cals JW, Schot MJ, de Jong SA, et al. Point-of-care C-reactive protein testing and antibiotic prescribing for respiratory tract infections: a randomized controlled trial. Ann Fam Med 2010; 8: 124-133.

21 Bronzwaer SL, Cars O, Buchholz U, et al. European Antimicrobial Resistance Surveillance System. A European study on the relationship between antimicrobial use and antimicrobial resistance. Emerg Infect Dis 2002; 8: 278-282.

22 Pérez-Trallero E, Martín-Herrero JE, Mazón A, et al. Spanish Surveillance Group for Respiratory Pathogens. Antimicrobial resistance among respiratory pathogens in Spain: latest data and changes over 11 years (1996-1997 to 2006-2007). Antimicrob Agents Chemother 2010; 54: 2953-2959.

23 Bjerrum L, Munck A, Gahrn-Hansen B, et al. Health Alliance for Prudent Prescribing, Yield and Use of Antimicrobial Drugs in the Treatment of Respiratory Tract Infections (HAPPY AUDIT). BMC Fam Pract 2010; 11: 29.

24 Munck A, Damsgaard J, Hansen DG, et al. The Nordic method for quality improvement in general practice. Quality Prim Care 2003; 11: 73-78.

25 Rabe-Hesketh S, Skrondal A. Multilevel and Longitudinal Modeling Using Stata. 2nd Edn. College Station, Stata Press, 2008.

26 Lervy B, Wareham K, Cheung WY. Practice characteristics associated with audit activity: a medical audit advisory group survey. Br J Gen Pract 1994; 44: 311-314.

27 Álvarez Carrera A, Martínez Cantarero C, Vidal Oliveras A, et al. Prescripción de antibióticos en el paciente ambulatorio [Antibiotic prescription in ambulatory patients]. Aten Primaria 2002; 30: 490-495.

28 Ochoa C, Eiros JM, Inglada L, et al. Assessment of antibiotic prescription in acute respiratory infections in adults. The Spanish Study Group on Antibiotic Treatments. J Infect 2000; 41: 73-83.

29 Picazo JJ, Pérez-Cecilia E, Herreras A. Estudio de las infecciones respiratorias extrahospitalarias. Estudio DIRA [Respiratory infections outside the hospital. DIRA study]. Enferm Infecc Microbiol Clin 2003; 21: 410-416.

30 Arnold SR, Straus SE. Interventions to improve antibiotic prescribing practices in ambulatory care. Cochrane Database Syst Rev 2005; 4: CD003539.

31 Melbye H, Berdal BP, Straume B, et al. Pneumonia: a clinical or radiographic diagnosis? Etiology and clinical features of lower respiratory tract infection in adults in general practice. Scand $J$ Infect Dis 1992; 24: 647-655.

32 van der Meer V, Neven AK, Broek PJ, et al. Diagnostic value of C reactive protein in infections of the lower respiratory tract: systematic review. BMJ 2005; 331: 26-29. 